\title{
Estimating Dietary Energy and Protein Requirements for Patients with Peripheral Arterial Disease: An Evaluation of Current Practice Amongst Dietitians
}

\author{
Jolene Thomas ${ }^{1}$, Hayley Leedham², Christopher Delaney ${ }^{3}$, J Ian Spark ${ }^{3}$ and Michelle Miller ${ }^{4 *}$ \\ ${ }^{1}$ Nutrition Lecturer, Nutrition and Dietetics, Flinders University, Bedford Park, South Australia, Australia \\ ${ }^{2}$ Accredited Practising Dietician, Nutrition and Dietetics, Flinders University, Bedford Park, South Australia, Australia \\ ${ }^{3}$ Department of Vascular Surgery, Nutrition and Dietetics, Flinders University, Bedford Park, South Australia, Australia \\ ${ }^{4}$ Head of Discipline, Nutrition and Dietetics, Flinders University, Bedford Park, South Australia, Australia
}

Received: November 06, 2014; Accepted: March 31, 2015; Published: April 10, 2015

*Corresponding author: Michelle Miller, Head of Discipline, Nutrition and Dietetics, Flinders University, Bedford Park, South Australia, Australia, Tel: +61 882045328; E-mail: michelle.miller@flinders.edu.au

\begin{abstract}
Aims: To (i) identify current practice of dietitians in determining energy and protein requirements for patients with Peripheral Arterial Disease (PAD); and (ii) explore the magnitude and implications of the variability in estimates with reference to typical patients at each stage of PAD.
\end{abstract}

Methods: An invitation to complete an online 26-item questionnaire was distributed electronically by the Dietitians Association of Australia to all members. Each method used by participants for estimation of energy and protein requirements across the stages of PAD was applied to the relevant typical patient and the range of estimates reported.

Results: Twenty-two dietitians completed the questionnaire and reported caseloads inclusive of all stages of PAD and with relatively equal frequency. For estimation of energy requirements, the Schofield equations in addition to $120-125 \mathrm{~kJ} / \mathrm{kg}$ and $125-145 \mathrm{~kJ} / \mathrm{kg}$ were most frequently used. When applied to the typical patient, the estimates of requirements varied by over $5000 \mathrm{~kJ} /$ day within each stage of PAD. For estimation of protein requirements it was common to apply the RDI $(0.8-1 \mathrm{~g} / \mathrm{kg} /$ day) or account for minor surgery or sepsis (up to $1.5 \mathrm{~g} / \mathrm{kg} /$ day) for patients with rest pain or tissue loss. The estimates of protein requirements varied by up to $55 \mathrm{~g} /$ day depending on the method used.

Conclusions: There was significant variation in energy and protein estimates both within and across the stages of PAD, which is possibly due to the little evidence available to inform dietitians on how to best treat patients with PAD. Further work is required to acquire a solid evidence base and subsequently communicate this for translation into practice.

Keywords: Energy requirements; Protein requirements; Peripheral arterial disease; Diet; Dietetic practice

\section{Introduction}

The role of nutrition in Peripheral Arterial Disease (PAD) is recognised in the management of risk factors of PAD development and progression with specific dietary and nutrient recommendations available for hypertension, dyslipidaemia, and diabetes [1-7]. Nutritional health is important for wound healing [8]. Evidence has shown that both obesity, a known risk factor for PAD, and underweight/under-nutrition, a risk factor for poor wound healing, are prevalent in PAD patients $[9,10]$. Those providing care for adults with PAD rely on dietitians to make an accurate determination of dietary energy and protein requirements and prescribe medical nutrition therapy accordingly, however there are currently no specific guidelines for estimating energy and protein requirements in PAD. Dietary energy prescriptions in excess of requirements can have a number of negative effects on clients, including increased likelihood of overweight [11] while excess protein can adversely affect bone and kidney function [12]. Underestimation of energy and protein requirements can lead to diminished wound healing capacity and poorer immune function [8]. In the absence of evidence-based recommendations, the aims of this study were to (i) identify current practice of dietitians in determining energy and protein requirements for patients with PAD; and (ii) explore the magnitude and implications of the variability in estimates with reference to typical patients at each of the established stages of PAD: asymptomatic, claudication, ischemic rest pain and tissue loss.

\section{Methods}

An invitation to complete an online, 26-item questionnaire created using Survey Monkey (Zoomerang Pro 2013) was administered to financial members of the Dietitians Association of Australia(DAA), thenational professional association for dietitians in Australia via a weekly email newsletter in February 2013. The Dillman Protocol [13] was followed to maximise response rate. Approval for this study was obtained from the Flinders University Social and Behavioural Research Ethics Committee (Approval number 5871). The questionnaire contained items regarding demographic characteristics of participants including 
clinical experience in the area of medical nutrition therapy for patients with PAD and whether the participant routinely treated patients with PAD with those answering 'no' directed to the end of the questionnaire and thanked for their participation. The remainder of the questionnaire comprised of 15 items designed to gain an insight into the dietetic practice of estimating energy and protein requirements for each clinical stage of PAD as defined by Rutherford and colleagues, [14] outlined in Table 1.

On receipt of the completed questionnaires the predictive equations for estimating energy and protein requirements that were most commonly reported by participants were applied to a 'typical patient' to gain an insight into the range and potential overlap of estimations by stage of PAD. Data for the typical asymptomatic PAD patient (ICD I70.20, $\mathrm{n}=622$ ), claudicant (ICD I70.21, $\mathrm{n}=384$ ), patient with ischemic rest pain (ICD I70.22, $\mathrm{n}=86$ ) and tissue loss (ICD I70.23, n=234) were obtained from the 45 and Up Study, the largest ongoing study of healthy ageing in the Southern Hemisphere and coordinated by the Sax Institute, New South Wales Australia [15]. The 'typical patient' for each stage of PAD based on the 45 and Up Study data was then used in all estimations of requirements in this study. Based on the information obtained regarding methods for energy and protein estimation, the authors developed a set of definitions based on evidence-based guidlines [16] for parameters used in estimation of energy and protein requirements. These are outlined in Table 2.

All de-identified data were imported from Survey Monkey into SPSS, version 19.0 (SPSS Inc, Chicago, IL, USA). Responses were displayed through the use of descriptive statistics to highlight trends. Continuous data were presented either as mean with 95\% confidence intervals or median with Inter Quartile Range (IQR) depending on the distribution of the data. All categorical data were displayed as frequency and percentages of participants with each response.

\section{Results}

Of 4918 eligible persons, 45 dietitians responded to the online questionnaire. Of these, 23 (51\%) did not routinely see PAD patients within their dietetic practice and therefore were not permitted to complete caseload and practice-based questions, providing a final sample size of 22 for the purpose of subsequent analyses. The methods of estimating energy and protein requirements used by participants according to each stage of PAD are shown in Table 3 and Table 4 respectively. The reasons provided for the selection of particular methods of estimating energy and protein requirements varied and included: training, clinical experience and evidence. Individual participants did not report altering the method used for estimation of energy requirements according to stage of PAD, however 10 (46\%) participants reported that they would alter the method used for estimating protein requirements according to stage of PAD with requirements increasing as PAD progressed. Tables 3 and 4 illustrate that application of the methods used by participants for estimating energy and protein requirements resulted in very little variation across the stages of PAD. The only variation occurred if a dietitian were to apply an adjustment factor to account for sepsis, in patients with rest pain or tissue loss, when estimating protein requirements. In contrast, within each stage of PAD, participants did report a variety of methods for calculating estimated energy and protein requirements resulting in a range of estimated energy requirements that varied by more than $5000 \mathrm{~kJ} /$ day and a variation of up to $55 \mathrm{~g}$ /day for protein requirements within each PAD stage.

\section{Discussion}

This small cross-sectional study found that in the absence of specific, evidence-based recommendations, respondents used a variety of methods when estimating either dietary energy or protein requirements for patients with PAD and the variability in estimates when applied to a typical patient, would be of sufficient magnitude to have a clinically meaningful impact on patient outcomes. Furthermore, this study found that adjustment for stage of PAD when estimating dietary energy requirements was uncommon.

The findings of the present study would indicate that evidence-based recommendations to guide dietitians when estimating the energy and protein requirements of patients with PAD would be worthwhile to improve consistency in approach. The study showed that dietitians in Australia recognise that there are additional dietary energy needs during times of wound healing however when these adjustments were applied to a typical patient it resulted in only $1,000 \mathrm{~kJ}$ extra. It might be argued that dietitians would review this estimation by monitoring body weight over time, and in the case of chronic arterial ulcers, this would be considered a valid argument. It is not however a valid

Table 1: Rutherford classifications for clinical stages of peripheral arterial disease and mean age and weight of typical patients at each of the stages.

\begin{tabular}{|c|c|c|c|}
\hline & Rutherford classification & $\begin{array}{l}\text { Mean age (yrs) of } \\
\text { typical patient }\end{array}$ & $\begin{array}{l}\text { Mean weight (kg) of typical } \\
\text { patient }^{\infty}\end{array}$ \\
\hline Stage 0 & Asymptomatic & $73.9(\mathrm{M}) 74.6(\mathrm{~F})$ & $81.6(\mathrm{M}) 67.2(\mathrm{~F})$ \\
\hline Stage 1 & Mild claudication & & \\
\hline Stage 2 & Moderate claudication & & \\
\hline Stage 3 & Severe claudication & $73.0(\mathrm{M}) 74.2(\mathrm{~F})^{\dagger}$ & $81.7(\mathrm{M}) 66.4(\mathrm{~F})^{\dagger}$ \\
\hline Stage 4 & Ischemic pain at rest & 75.2(M) 77.1(F) & 79.4(M) 63.3(F) \\
\hline Stage 5 & Ischemic ulceration not exceeding ulcer of the digits of the foot & & \\
\hline Stage 6 & Severe ischemic ulcers or gangrene & $78.8(\mathrm{M}) 81.8(\mathrm{~F})^{\ddagger}$ & $79.7(\mathrm{M}) 64.7(\mathrm{~F})^{\ddagger}$ \\
\hline
\end{tabular}

†Data represents mean age and weight of stage $1-3, \neq$ Data represents mean age and weight of stages 5-6, $\infty$ Data for a typical patient obtained from the 45 and Up Study ${ }^{15}$ 
Table 2: Author definitions of parameters utilized by Australian dietitians in the estimation of energy and protein requirements in PAD.

\begin{tabular}{|l|l|}
\hline \multicolumn{1}{|c|}{ Parameter reported by survey participants } & \multicolumn{1}{c|}{ Definition utilized by authors } \\
\hline Actual Body Weight (ABW) & Current body weight on presentation \\
\hline Ideal Body Weight (IBW) & Body weight representative of Body Mass Index 22.5kg.m² \\
\hline Adjusted ideal body weight (AiBW) & Weight at the mid-point between ABW and IBW \\
\hline Weight loss factor (WLF) & Deficit of 2143kJ/day from the estimated energy requirements to induce $0.5 \mathrm{~kg}$ weight loss/week. \\
\hline
\end{tabular}

Table 3: Estimated Energy Requirements of a typical patient across the stages of PAD utilising the methods reported by Dietitians in Australia.

\begin{tabular}{|c|c|c|c|c|c|c|c|c|}
\hline & \multicolumn{2}{|c|}{ Asymptomatic } & \multicolumn{2}{|c|}{ Claudication } & \multicolumn{2}{|c|}{ Rest pain } & \multicolumn{2}{|c|}{ Tissue Loss } \\
\hline & Male & Female & Male & Female & Male & Female & Male & Female \\
\hline EER (Schofield x 1.2) & 7747 & 6369 & 7757 & 6332 & 7617 & 6192 & 7638 & 6257 \\
\hline EER (Schofield x 1.2, WLF $0.5 \mathrm{~kg}$ ) & 5604 & 4226 & 5614 & 4189 & 5474 & 4049 & 5495 & 4114 \\
\hline $\begin{array}{l}\text { Non-ambulatory or sedentary, not } \\
\text { hypermetabolic }(100-120 \mathrm{kj} / \mathrm{kg})\end{array}$ & $8158-9790$ & $6719-8063$ & 8174-9809 & $6637-7964$ & 7936-9523 & $6330-7596$ & $7972-9566$ & $6472-7766$ \\
\hline $\begin{array}{l}\text { Slightly hypermetabolic, post-operative, } \\
\text { repletion, infection(120-145kj } / \mathrm{kg})\end{array}$ & - & - & $\begin{array}{l}9809- \\
11853\end{array}$ & 7964-9624 & $\begin{array}{l}9523- \\
11507\end{array}$ & 7596-9179 & $\begin{array}{l}9566- \\
11559\end{array}$ & $7766-9384$ \\
\hline $\begin{array}{l}\text { Hypermetabolic, severely stressed, } \\
\text { malabsorption, major trauma, sepsis (145- } \\
160 \mathrm{kj} / \mathrm{kg} \text { ) }\end{array}$ & - & - & - & - & - & - & $\begin{array}{l}11559- \\
12755\end{array}$ & $\begin{array}{l}9384- \\
10355\end{array}$ \\
\hline $120-125 \mathrm{kj} / \mathrm{kg}$ & $\begin{array}{l}9790- \\
10198\end{array}$ & 8063-8399 & $\begin{array}{l}9809- \\
10218\end{array}$ & 7964-8296 & 9523-9920 & 7596-7913 & 9566-9965 & $7766-8090$ \\
\hline $125-145 \mathrm{kj} / \mathrm{kg}$ & $\begin{array}{l}10198- \\
11829\end{array}$ & 8399-9743 & $\begin{array}{l}10218- \\
11853\end{array}$ & 8296-9624 & $\begin{array}{l}9920- \\
11507\end{array}$ & 7913-9179 & $\begin{array}{l}9965- \\
11559\end{array}$ & 8090-9384 \\
\hline
\end{tabular}

WLF - Weight loss factor of 2143kJ/day

Table 4: Estimated protein requirements of a typical patient across the stages of PAD utilising the methods reported by Dietitians in Australia.

\begin{tabular}{|l|c|c|c|c|c|c|c|c|}
\hline Method of estimation & \multicolumn{2}{|c|}{ Asymptomatic } & \multicolumn{2}{|c|}{ Claudication } & \multicolumn{2}{l|}{ Rest pain } & \multicolumn{2}{l|}{ Tissue Loss } \\
\hline & Male & Female & Male & Female & Male & Female & Male & Female \\
\hline EPR (RDI 0.8g/kg) & 65.2 & 53.8 & 65.4 & 53.1 & 63.5 & 50.6 & 63.8 & 51.8 \\
\hline EPR (RDI 0.85g/kg) & 69.3 & 57.1 & 69.5 & 56.4 & - & - & - & - \\
\hline EPR (RDI 1g/kg) & 81.5 & 67.2 & 81.7 & 66.4 & 79.4 & 63.3 & 79.7 & 64.7 \\
\hline Minor Surgery (1g/kg) & 81.5 & 67.2 & 81.7 & 66.4 & 79.4 & 63.3 & 79.7 & 64.7 \\
\hline Minor Surgery (1.2g/kg) & 97.8 & 80.6 & 98.1 & 79.6 & 95.2 & 76.0 & 95.7 & 77.7 \\
\hline Sepsis (1.2-/kg) & - & - & - & - & 95.2 & 76.0 & 95.7 & 77.7 \\
\hline Sepsis (-1.5g/kg) & - & - & - & - & 119.0 & 95.0 & 119.6 & 97.1 \\
\hline
\end{tabular}

argument to suggest that there are no differences in dietary energy requirements between the other three stages of PAD $[17,18]$ and that monitoring would allow for adjustments as asymptomatic patients and those with claudication or rest pain would rarely be seen regularly enough to detect clinically meaningful changes in body weight. The magnitude of the variability in estimates observed in this study could translate to a concerning potential weight gain or loss of more than $1 \mathrm{~kg} /$ week in males and $0.5-1 \mathrm{~kg} /$ week in females.

Unlike estimates of energy requirements, some dietitians in this study did report that they were likely to adjust dietary protein requirements with stage of PAD. Despite this, when the adjustment factors reported were applied to the typical patient, the dietary protein requirements for those with sepsis, rest pain or tissue loss were similar to estimates for asymptomatic PAD patients and those with claudication. Conventional management of these patients is supervised exercise training and emerging evidence suggests that repeated exposure to ischemic reperfusion injury initiates muscle atrophy, specifically in the symptomatic leg [19]. Accurate dietary protein estimates and prescription is likely critical in the prevention of this adverse outcome.

It is important to declare that this study is not devoid of limitations and hence interpretation of the findings should be considered with caution. The small sample of dietitians $(n=22)$ who responded to the questionnaire is one important limitation that may impact on the generalisability of the findings. The widely accepted Dillman Protocol for Web-Based Surveys [13] was used with the intention to maximise response rates through the use of reminder emails and simple questionnaire design. The sample included dietitians Australia-wide and it is interesting 
to note that their characteristics were not dissimilar to those of the DAA member population according to the 2011 DAA Annual Report [20]. Some of the assumptions made in the calculations of requirements for the typical patients may not be truly reflective of the intentions of those completing the questionnaire. We multiplied BMR by an activity factor of 1.2 across all stages of PAD for our estimations of energy requirements however it could be argued that a higher activity factor would be more applicable for asymptomatic patients. Notwithstanding the validity of this argument, the net result of a higher activity factor would be minimal $(\sim 500 \mathrm{~kJ}$ for an increase to 1.3$)$ and it would not affect our findings relating to the large variation in estimating requirements of both energy and protein within each stage of PAD.

The accurate determination of dietary energy and protein requirements for PAD patients should be a priority area of research. The rate of growth in the aging population of western countries, in conjunction with a rise in Type 2 diabetes mellitus and overweight/obesity will see the number of PAD patients increase within the next decade and beyond. There was significant variation in energy and protein estimates within this study which is possibly due to the little evidence available to inform dietitians on how to best treat this patient group. Therefore, the creation of new evidence from well designed studies with larger sample sizes investigating the energy and protein requirements, and the development and communication of evidence-based guidelines on how to adequately provide nutritional care to PAD patients is an urgent area for further research. In the interim, dietitians should use available equations for estimating requirements with caution and closely monitor the nutritional intake and nutritional status of this patient group allowing adjustment of estimates over time.

\section{References}

1. American Dietetic Association. Hypertension evidence based nutrition practice guideline. American Dietetic Association, editor. Chicago (IL). 2008.

2. National Heart Foundation. Heart Foundation Guide to management of hypertension 2008.

3. National Vascular Disease Prevention Alliance. Guidelines for the management of absolute cardiovascular disease risk 2012.

4. Jellinger PS, Smith DA, Mehta AE, Ganda O, Handelsman Y, Rodbard HW, et al. American Association of Clinical Endocrinologists' Guidelines for Management of Dyslipidaemia and prevention of Atherosclerosis: executive summary. Endocr Pract. 2012; 18(2): 269-93.

5. Dyson PA, Kelly T, Deakin T, Duncan A, Frost G, Harrison Z, et al Diabetes UK Nutrition Working group. Evidence-based nutrition guidelines for the prevention and management of Diabetes. Diabet Med. 2011; 28(11): 1282-8. doi: 10.1111/j.1464-5491.2011.03371.x.
6. Evert AB, Boucher JL, Cypress M, Dunbar SA, Franz MJ, Mayer-Davis EJ, et al. Nutrition therapy recommendations for the management of adults with diabetes. Diabetes Care. 2013; 36(11): 3821-42. doi: 10.2337/dc13-2042.

7. Dietitians Association of Australia New South Wales Branch Diabetes Interest Group. Evidence based practice guidelines for the nutritional management of Type 2 Diabetes Mellitus for Adults. Canberra, ACT: 2011.

8. Flancbaum L, Choban PS, Sambucco S, Verducci J, Burge JC. Comparison of indirect calorimetry, the Fick method, and prediction equations in estimating the energy requirements of critically ill patients. Am J Clin Nutr. 1999; 69(3): 461-6.

9. Lavie CJ, Milani RV, Ventura HO. Obesity and Cardiovascular Disease: Risk Factor, Paradox, and Impact of Weight Loss. J Am Coll Cardiol. 2009; 53(21): 1925-32. doi: 10.1016/j.jacc.2008.12.068.

10. De Waele E, Leslie Moerman, Kobe V Bael, Dimitri Aerden, Erik Debing, Patrick M Honoré, et al. High Incidence of malnutrition in elective vascular surgery patients: An observational auditing study. JTrans Int Med. 2014; 2(1):32-5.

11. Romieu I, Willett WC, Stampfer MJ, Colditz GA, Sampson L, Rosner B, et al. Energy intake and other determinants of relative weight. Am J Clin Nutr. 1988; 47(3): 406-12.

12. Sellmeyer DE, Stone KL, Sebastian A, Cummings SR. A high ratio of dietary animal to vegetable protein increases the rate of bone loss and the risk of fracture in postmenopausal women. Study of Osteoporotic Fractures Research Group. Am J Clin Nutr. 2001; 73(1): 118-22.

13. Dillman DA. Mail and internet surveys: The tailored design method. New York: Wiley; 2000.

14. Rutherford RB, Baker JD, Ernst C, Johnston KW, Porter JM, Ahn S, et al. Recommended standards for reports dealing with lower extremity ischemia: Revised version. J Vasc Surg. 1997; 26(3): 517-38.

15. Sax Institute: The 45 and Up Study.

16. National Health and Medical Research Council. Nutrient Reference Values for Australia and New Zealand Including Recommended Dietary Intakes. In: Commonwealth of Australia, editor. Canberra, ACT2006.

17. Gardner AW, Montgomery PS. Resting energy expenditure in subjects with and without intermittent claudication. Metabolism. 2009; 58(7): 1008-1012. doi: 10.1016/j.metabol.2009.02.030.

18. Gardner AW, Montgomery PS. Resting energy expenditure in patients with intermittent claudication and critical limb ischemia. J Vasc Surg. 2010; 51(6): 1436-1441. doi: 10.1016/j.jvs.2009.12.072.

19. Delaney CL, Miller MD, Chataway TK, Spark JI. A Randomised Controlled Trial of Supervised Exercise Regimens and their Impact on Walking Performance, Skeletal Muscle Mass and Calpain Activity in Patients with Intermittent Claudication. Eur J Vasc Endovasc Surg. 2014; 47(3): 304-10. doi: 10.1016/j.ejvs.2013.12.021.

20. Dietitians Association of Australia. Annual Report. Canberra, ACT: 2011. 